\title{
АНАЛИЗ ВЛИЯНИЯ ГЕОЛОГО-ТЕХНОЛОГИЧЕСКИХ ПОКАЗАТЕЛЕЙ НА ЭФФЕКТИВНОСТЬ ТЕХНОЛОГИИ РАДИАЛЬНОГО БУРЕНИЯ НА ПРИМЕРЕ ЭКСПЛУАТАЦИОННЫХ ОБЪЕКТОВ ПЕРМСКОГО КРАЯ
}

\author{
Кочнев Александр Александрович', \\ sashakoch93@gmail.com \\ Зотиков Владимир Иванович', \\ vladimirzotikov@yandex.ru \\ Галкин Сергей Владиславович', \\ doc_galkin@mail.ru \\ 1 Пермский национальный исследовательский политехнический университет,
Россия, 614990, г. Пермь, Комсомольский пр., 29.
}

Актуальность. С целью стабилизации добычи нефти на месторождениях Пермского края, активно используются методы повышения нефтеотдачи. Среди мероприятий, направленных на увеличение продуктивности скважин, наибольшее применение получили соляно-кислотные обработки, гидроразрыв пласта, радиальное бурение. Для вовлечения в разработку не дренируемых участков в настоящее время применяют бурение боковых стволов, многоствольное бурение и различные виды гидроразыва пласта. Однако подобные операции в связи с их высокой стоимостью не всегда экономически оправданы. Технология радиального бурения является менее затратной альтернативой указанным мероприятиям. Метод радиального бурения при правильном подборе скважин-кандидатов может оказаться наиболее эффективным. При успешном его применении можно задействовать не дренируемые пропластки, увеличив долю извлекаемых запасов. Эффективность радиального бурения определяется геологотехнологическими условиями скважин, вместе с тем в настоящее время нет четких критериев оценки условий применения данного метода. Анализ эффективности радиального бурения с разработкой рекомендаций к применению может значительно повысить практическую эффективность данного метода.

Цель: выявление геологических, гидродинамических и технологических критериев для успешного применения радиального бурения на месторождениях Пермского края.

Объект: нефтедобывающие скважины месторождений Пермского края, на которых проведены операции по радиальному бурению. Методика исследования основана на использовании известных методов математической статистики.

Результаты. Проведен анализ эффективности технологии радиального бурения по Пермскому краю. Создана общая база по скважинам с радиальным бурением, в которую включены геологические, гидродинамические и технологические параметры. Выделены параметры, которые оказывают наиболее значимое влияние на успешность проведения мероприятия. Разработаны палетки для прогноза среднесуточного прироста дебита нефти от технологии радиального бурения на территории Пермского края.

\section{Ключевые слова:}

Радиальное бурение, соляно-кислотная обработка скважин, нефтедобыча,

t-критерий Стьюдента, дебит, методы повышения нефтеотдачи пласта.

\section{Введение}

Большинство эксплуатационных объектов нефтяных месторождений Пермского края сегодня находится на третьей стадии разработки с падающей добычей $(66 \%)$. Остаточные запасы залежей при этом приурочены преимущественно к низкопроницаемым коллекторам, дренирование флюидов в которых затруднено. Для поддержания темпов добычи для таких эксплуатационных объектов применяются методы повышения нефтеотдачи пласта (ПНП). В Пермском крае среди геолого-технических мероприятий (ГТМ), направленных на увеличение продуктивности скважин, наибольшее применение получили соляно-кислотные обработки (СКО), гидроразрыв пласта (ГРП), радиальное бурение (РБ). В работе [1] приведены осредненные годовые показатели эффективности ГТМ последних лет, согласно которым для технологии СКО эффективность составляла от 38 до $48 \%$, для ГРП - от 38 до $49 \%$, для РБ - от 42 до $78 \%$. Эффективность ГТМ в работе [1] оценивалась как достиже- ние запланированного дебита по нефти. Перечисленные выше технологии могут рассматриваться как конкурирующие при выборе ГТМ на скважинах. Выбор технологии должен базироваться на анализе ее эффективности в конкретных геологотехнологических условиях разработки.

К настоящему времени в Пермском крае за относительно короткий срок (около 10 лет) технология РБ заняла значительную нишу для скважин с падающей добычей, которые в конце своего срока службы дают очень малый дебит. При этом подбор скважин-кандидатов осуществляется согласно следующим основным требованиям: обводненность ниже $40 \%$, пластовое давление выше давления насыщения, дебит нефти ниже 10 т/сут. Радиальные каналы закладываются в направлении наибольшей плотности остаточных запасов.

Для Ножовской и Осинской групп месторождений технология РБ является основной, среди рассмотренных ГТМ. РБ может рассматриваться как альтернатива ГРП для скважин с более низкими 
требованиями по качеству цемента или состояния эксплуатационной колонны. Кроме этого, технология РБ значительно более дешева в сравнение с ГРП [2], что особенно важно для скважин с небольшой нефтенасыщенной толщиной. Необходимо заметить, что в условиях старого фонда скважин с каждым годом все сложнее подобрать подходящие скважины для ГРП, что делает технологию РБ актуальной в перспективе [3].

Радиальное бурение является разработкой компании Rad Tech International Inc, первые опытнопромышленные работы технологии датируются концом 70-х гг. Принцип работы РБ заключается в том, что на нужную глубину спускается инструмент для фрезерования обсадной колонны, затем гибкую фрезу вынимают и спускают гибкую насосно-компрессорную трубу с гидромониторной насадкой. Насосами подается жидкость под большим давлением, и за счет гидромониторного воздействия намывается радиальный канал [4]. Время проходки составляет около 20 минут, длина канала не более 100 м, количество радиальных каналов не ограничено, но чаще от 2 до 4 штук. После бурения радиальные каналы промываются кислотными составами для прочистки от кольматации.

Данный метод не только интенсифицирует добычу, но и повышает степень нефтеизвлечения запасов, вовлекая в добычу неработающие пропластки $[5,6]$. При этом радиальные каналы могут увеличивать производительность скважин в 3-4 раза. Согласно опыту работ [7-10], технология РБ в большей степени эффективна в условиях высоковязких нефтей, для которых наиболее вероятно образование застойных зон в малопроницаемых интервалах геологического разреза. В идеале технология создания радиальных глубокопроникающих каналов фильтрации позволяет многократно увеличить площадь фильтрации флюидов к стволу скважины. Согласно данным работы [11], РБ может рассматриваться, в том числе, как альтернатива бурению боковых стволов со сверхмалыми радиусами.

Существует мнение, что әффективность радиального бурения напрямую зависит от эффективности кислотной обработки, проведенной после РБ. Однако в работах $[12,13]$ для территории исследования по результатам статистического анализа установлено, что метод РБ позволяет достичь большего прироста дебита нефти, чем СКО.

В настоящее время для месторождений Пермского края отмечен некоторый спад эффективности РБ. Кроме этого, нет четких критериев применимости данного метода. Необходимо более детально подходить к выбору скважин, учитывая геолого-технологические особенности разработки объектов [14]. Международный опыт выявления оптимальных геолого-технологических параметров для технологии РБ рассмотрен в работах [15-17].

\section{Анализ эффективности технологии радиального бурения}

Несмотря на положительную в целом эффективность внедрения РБ в Пермском крае, необходимо заметить, что в период резкого увеличения количества мероприятий РБ доля ГТМ, признанных успешными, заметно снижалась (до 42 \%). При более строгом планировании мероприятий РБ с уменьшением их количества годовые показатели успешности увеличились до 68-78 \% . Все это показывает необходимость тщательного выбора объектов для реализации технологии РБ и комплексного анализа эффективности метода. Результатом этого будет выделение оптимальных геолого-технологических условий его внедрения. Отдельной задачей является оценка динамики темпов снижения дебитов нефти и времени технологического эффекта от РБ.

По состоянию на 01.01.2017 г. на месторождениях Пермского края проведено 590 операций РБ на 538 скважинах (рис. 1).

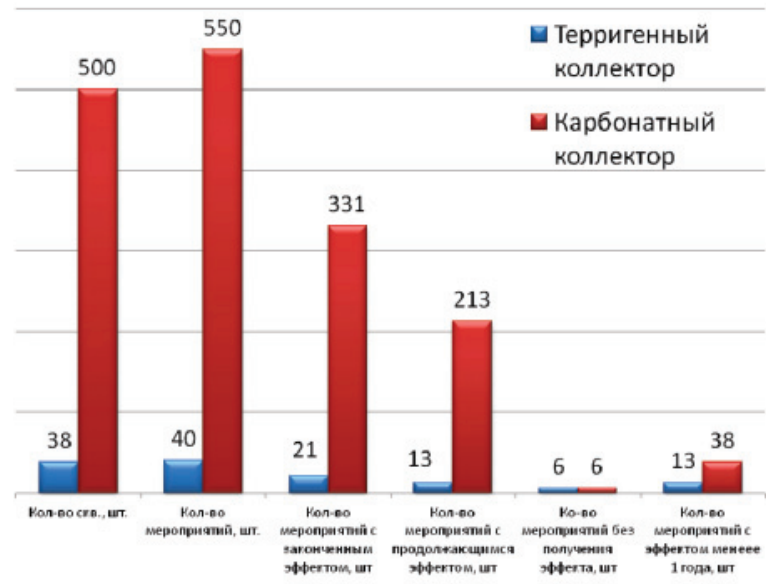

Pис. 1. Общая характеристика применения РБ

Fig. 1. General characteristics of the radial drilling (RD) application

Из рис. 1 видно, что число операций РБ в карбонатном коллекторе (550 штук) на порядок превышает их количество в терригенном (40 штук). В целом все осредненные показатели эффективности значительно выше для карбонатных коллекторов. Средняя дополнительная добыча нефти составила 4573 т на скважину в карбонатных против 3555 т в терригенных коллекторах. Причем для терригенных коллекторов эффект от РБ продолжался менее 1 года в трети мероприятий, а в $15 \%$ ГТМ эффект составил менее 2 т.

Для карбонатных коллекторов доля ГТМ с эффектом менее 1 года составила 7 \%, а доля отрицательных результатов составила лишь $1 \%$. Помимо большей наработки технологии, основной причиной большей эффективности РБ в карбонатном разрезе является ее комплексирование с кислотной обработкой. В терригенных коллекторах тех- 
нология РБ во всех случаях не дополнялась СКО. Также среди возможных причин снижения эффективности метода в терригенном разрезе можно выделить набухание глин, кольматацию каналов, эффект Жамена, а также часто высокую степень выработки запасов в момент реализации РБ.

Разная эффективность и технология проведения ГТМ определяет необходимость раздельного изучения карбонатных и терригенных коллекторов при анализе эффективности РБ.

При анализе дополнительной добычи нефти $\left(Q_{\text {доп }}\right)$ и времени эффекта $\left(T_{\text {гтм }}\right)$ от ГТМ необходимо раздельно изучать скважины с закончившимся и с не закончившимся эффектом. Так, для скважин с закончившимся эффектом общая величина $Q_{\text {доп }} c$ ставила 891,1 тыс. т против 1675 тыс. т для скважин с не закончившимся эффектом. Средняя продолжительность эффекта по скважинам с закончившимся эффектом составила 818 для карбонатных и 667 суток для терригенных пластов. По скважинам с не законченным эффектом среднее время эффекта (даже несмотря на то, что он еще не закончен) составляет 1522 и 1070 суток для карбонатных и терригенных объектов. Таким образом, именно скважины с незаконченным эффектом имеют наибольший эффект от ГТМ. Их недоучет приведет не только к потере важной информации, но и к систематическому занижению истинной эффективности метода. С учетом этого, для скважин с незаконченным эффектом использовалась вся фактическая информация, для оценки их показателей на поздних этапах использовался линейный тренд снижения добычи нефти.

\section{Оценка влияния геологических}

\section{и гидродинамических параметров}

\section{на эффективность радиального бурения}

Для статистического анализа использовались следующие параметры скважин: нефтенасыщенная толщина $\left(h_{\mathrm{H}}, \mathrm{M}\right)$; пористость $\left(K_{\text {п }}, \%\right)$; начальная нефтенасыщенность $\left(K_{\text {н }}\right.$, д.ед.); проницаемость по ГДИ $\left(k_{\text {гди }}\right.$, мкм $\left.^{2}\right)$; коэффициент песчанистости $\left(K_{\text {песч }}\right.$, д.ед.); коэффициент расчлененности $\left(K_{\text {расч}}\right.$, ед.); вязкость и плотность нефти в пластовых условиях $\left(\mu, \mathrm{м} \Pi а \cdot c ; \rho_{\text {н }}, \Gamma / \mathrm{cm}^{3}\right) ;$ объемный коэффициент нефти $(b$, д.ед.); содержание парафина в нефти (ПР, $\%)$; средняя газонасыщенность $\left(G, \mathrm{~m}^{3} / \mathrm{M}^{3}\right)$; гидропроводность призабойной зоны пласта (ПЗП), $\left(\varepsilon_{\text {пзп }}\right.$, $\left.\mathrm{MKM}^{2} \cdot \mathrm{cm} / \mathrm{MПа} \cdot \mathrm{c}\right)$; гидропроводность удаленной $30^{-}$ ны пласта (УЗП) $\left(\varepsilon_{\text {узп }}, \mathrm{Mkм}^{2} \cdot \mathrm{cm} / \mathrm{м} \Pi а \cdot \mathrm{c}\right) ;$ коэффициент проницаемости ПЗП $\left(k_{\text {пв }}, \mathrm{м \kappa м}^{2}\right)$; коэффициент проницаемости УЗП $\left(k_{\text {узп }}\right.$, мкм $\left.^{2}\right)$; пьезопроводность $\left(\chi, \mathrm{cm}^{2} \cdot c\right)$; пластовое давление $\left(P_{\text {пл }}, \mathrm{MПа);} \mathrm{забойное}\right.$ давление $\left(P_{\text {заб }}, \mathrm{MПа);} \mathrm{давление} \mathrm{насыщения}\left(P_{\text {нас }}\right.\right.$, МПа); средняя толщина единичного нефтенасыщенного пропластка ( $h_{\text {пр }}$ м, рассчитывалась как отношение $h_{\text {н }}$ к количеству нефтенасыщенных пропластков); скин-фактор скважины $(S)$.

Первоначально для установления зависимостей между геологическими и технологическими параметрами использовался корреляционный ана- лиз. Однако статистически значимых коэффициентов корреляции установить не удалось. Самый высокий коэффициент корреляции отмечен между средним приростом за первый год и остаточной плотностью запасов $(r=0,52)$. Зависимость показывает, что чем больше плотность извлекаемых запасов на скважину, тем больший прирост от радиального бурения за первый год. Для оценки влияния геолого-технологических параметров на эффективность РБ проведена проверка гипотезы о равенстве средних значений в двух выборках с помощью $t$-критерия Стьюдента. Под показателями эффективности принимались: суммарная дополнительная добыча нефти от РБ, среднесуточный прирост дебита, продолжительность эффекта и максимальный дебит нефти после РБ.

Таблица 1. Влияние геологических факторов на параметры добычи нефти для скважин с карбонатным коллектором

Table 1. Influence of geological factors on oil production parameters for wells with carbonate reservoir

\begin{tabular}{|c|c|c|c|c|c|c|}
\hline $\begin{array}{c}\text { Дополнительная } \\
\text { добыча нефти, т } \\
\text { Additional oil } \\
\text { production, t }\end{array}$ & $<2200$ & $>2200$ & $\begin{array}{c}t \text {-критерий } \\
\text {-value }\end{array}$ & $p$ & $N_{1}$ & $\mathrm{~N}_{2}$ \\
\hline$K_{n}, \%$ & 13,8 & 14,1 & $-1,8$ & 0,06 & 270 & 264 \\
\hline 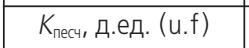 & 0,37 & 0,38 & $-1,7$ & 0,09 & 275 & 271 \\
\hline$\mu, \mathrm{M} П \mathrm{a} \cdot \mathrm{c}(\mathrm{mPa} \cdot \mathrm{s})$ & 16,6 & 20,2 & $-2,0$ & 0,04 & 275 & 271 \\
\hline$\rho_{\mathrm{H}}, \Gamma / \mathrm{CM}^{3}\left(\mathrm{~g} / \mathrm{sm}^{3}\right)$ & 0,85 & 0,86 & $-1,7$ & 0,07 & 274 & 271 \\
\hline b, д.ед. (u.f) & 1,08 & 1,07 & 1,8 & 0,07 & 275 & 271 \\
\hline$G, M^{3} / M^{3}\left(m^{3} / m^{3}\right)$ & 42,2 & 36,6 & 1,9 & 0,05 & 274 & 271 \\
\hline $\begin{array}{c}\text { Среднесуточный } \\
\text { прирост, т/сут } \\
\text { Growth factor, t/day }\end{array}$ & $<2,7$ & $>2,7$ & $\begin{array}{c}t \text {-критерий } \\
t \text {-value }\end{array}$ & $p$ & $N_{1}$ & $\mathrm{~N}_{2}$ \\
\hline$K_{н}$, д.ед. (u.f) & 0,741 & 0,754 & $-2,7$ & $<0,01$ & 278 & 256 \\
\hline$K_{\text {расч }}$, ед. $(u)$ & 6,5 & 7,3 & $-2,2$ & 0,02 & 279 & 261 \\
\hline$\mu, \mathrm{M} \Pi \mathrm{a} \cdot \mathrm{c}(\mathrm{mPa} \cdot \mathrm{s})$ & 17,0 & 19,9 & $-1,7$ & 0,08 & 279 & 261 \\
\hline$\Pi P, \%$ & 3,4 & 3,5 & $-1,7$ & 0,07 & 278 & 261 \\
\hline$P_{\text {нас, }}$ МПа (MРа) & 9,0 & 9,5 & $-2,8$ & $<0,01$ & 279 & 260 \\
\hline $\begin{array}{c}\text { Продолжитель- } \\
\text { ность эффекта от } \\
\text { РБ, сут } \\
\text { Duration of the ef- } \\
\text { fect of RD, day }\end{array}$ & $<870$ & $>870$ & $\begin{array}{c}t \text {-критерий } \\
t \text {-value }\end{array}$ & $p$ & $N_{1}$ & $N_{2}$ \\
\hline$K_{\mathrm{n}}, \%$ & 13,7 & 14,1 & $-2,1$ & 0,03 & 264 & 270 \\
\hline К песч, д.ед. (u.f) & 0,3 & 0,4 & $-2,0$ & 0,04 & 269 & 277 \\
\hline$\rho_{\mathrm{H}}, \Gamma / \mathrm{CM}^{3}\left(\mathrm{~g} / \mathrm{sm}^{3}\right)$ & 0,8 & 0,9 & $-1,8$ & 0,06 & 268 & 277 \\
\hline b, д.ед. (u.f) & 1,1 & 1,1 & 2,0 & 0,04 & 269 & 277 \\
\hline$\Pi P, \%$ & 3,4 & 3,5 & $-1,8$ & 0,07 & 268 & 277 \\
\hline$G, \mathrm{M}^{3} / \mathrm{M}^{3}\left(\mathrm{~m}^{3} / \mathrm{m}^{3}\right)$ & 41,8 & 37,2 & 1,6 & 0,10 & 268 & 277 \\
\hline $\begin{array}{l}\text { Мах дебит нефти } \\
\text { после РБ, т/сут } \\
\text { Max oil production } \\
\text { rate after RD, t/day }\end{array}$ & $<10$ & $>10$ & $\begin{array}{c}t \text {-критерий } \\
t \text {-value }\end{array}$ & $p$ & $N_{1}$ & $\mathrm{~N}_{2}$ \\
\hline$h_{\mathrm{H}} \mathrm{M}(\mathrm{m})$ & 5,8 & 7,8 & $-4,1$ & $<0,01$ & 281 & 261 \\
\hline 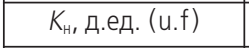 & 0,74 & 0,75 & $-1,5$ & 0,10 & 282 & 258 \\
\hline$K_{\text {расч, }}$ ед. $(\mathrm{u})$ & 6,3 & 7,6 & $-3,6$ & $<0,01$ & 283 & 263 \\
\hline$P_{\text {нас, }} \mathrm{MПа} \mathrm{(MPa)}$ & 9,0 & 9,5 & $-2,8$ & $<0,01$ & 283 & 262 \\
\hline
\end{tabular}


Таблица 2. Влияние гидродинамических факторов на параметры добычи нефти для скважин с карбонатным коллектором

Table 2. Influence of hydrodynamic factors on oil production parameters for wells with carbonate reservoir

\begin{tabular}{|c|c|c|c|c|c|c|}
\hline $\begin{array}{c}\text { Дополнительная } \\
\text { добыча нефти, т } \\
\text { Additional oil pro- } \\
\text { duction, t }\end{array}$ & $<2480$ & $>2480$ & $\begin{array}{c}t \text {-критерий } \\
t \text {-value }\end{array}$ & $p$ & $N_{1}$ & $\mathrm{~N}_{2}$ \\
\hline $\begin{array}{c}\mathcal{E}_{\text {пзп, }} \\
\mathrm{MKM}^{2} \cdot \mathrm{CM} /(\mathrm{M} \sqcap \mathrm{M} \cdot \mathrm{C})\end{array}$ & 1,2 & 2,0 & $-2,3$ & $<0,01$ & \multirow{4}{*}{171} & \multirow{4}{*}{17} \\
\hline$\chi, \mathrm{CM}^{2} \cdot c\left(\mathrm{sm}^{2} \cdot \mathrm{s}\right)$ & 120,5 & 213,0 & $-1,8$ & 0,07 & & \\
\hline$P_{\text {заб, }} \mathrm{MПа} \mathrm{(MPa)}$ & 4,5 & 5,2 & $-2,4$ & 0,02 & & \\
\hline скин-фактор S & $-2,8$ & $-1,7$ & $-3,1$ & $<0,01$ & & \\
\hline $\begin{array}{c}\text { Среднесуточный } \\
\text { эффект, т/сут } \\
\text { Growth factor, t/day }\end{array}$ & $<2,7$ & $>2,7$ & $\begin{array}{c}t \text {-критерий } \\
t \text {-value }\end{array}$ & $p$ & $N_{1}$ & $\mathrm{~N}_{2}$ \\
\hline $\begin{array}{c}\varepsilon_{y_{3 n}, \mathrm{MKM}^{2} \cdot \mathrm{cM} / \mathrm{M} П \mathrm{M} \cdot \mathrm{c}}(\mathrm{mkm} \cdot \mathrm{sm} / \mathrm{mPa} \cdot \mathrm{s}) \\
\end{array}$ & 0,9 & 2,3 & $-3,6$ & $<0,01 \mid$ & 177 & 165 \\
\hline $\begin{array}{c}K_{\text {продя, }} \mathrm{M}^{3} / \text { сут } / \mathrm{M} П а \\
\left(\mathrm{~m}^{3} / \mathrm{d} / \mathrm{MPa}\right)\end{array}$ & 1,2 & 2,0 & $-2,7$ & $<0,01$ & 120 & 135 \\
\hline$k_{\mathrm{y} 3 n}, \mathrm{MKM}^{2}\left(\mathrm{mkm}^{2}\right)$ & 0,027 & 0,061 & $-1,9$ & 0,06 & 176 & 163 \\
\hline$\chi_{1} \mathrm{CM}^{2} \cdot \mathrm{c}\left(\mathrm{sm}^{2} \cdot \mathrm{s}\right)$ & 86,9 & 252,4 & $-3,2$ & $<0,01$ & 177 & 165 \\
\hline$P_{\text {пл, }}, \mathrm{M} а$ ( $(\mathrm{MPa})$ & 10,3 & 11,2 & $-2,5$ & 0,01 & 177 & 164 \\
\hline$P_{\text {заб, }}$ МПа (MPa) & 4,2 & 5,6 & $-5,1$ & $<0,01$ & 177 & 165 \\
\hline скин-фактор S & $-2,8$ & $-1,7$ & $-3,4$ & $<0,01$ & 177 & 165 \\
\hline $\begin{array}{c}\text { Продолжитель- } \\
\text { ность эффекта, сут } \\
\text { Duration of the ef- } \\
\text { fect of RD, day }\end{array}$ & $<900$ & $>900$ & $\begin{array}{c}t \text {-критерий } \\
t \text {-value }\end{array}$ & $p$ & $N_{1}$ & $\mathrm{~N}_{2}$ \\
\hline 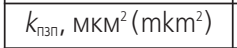 & 0,068 & 0,039 & 1,8 & 0,07 & 66 & 73 \\
\hline$P_{\text {пл, }}, \mathrm{M} а$ ( $(\mathrm{MPa})$ & 10,3 & 11,1 & $-2,0$ & 0,04 & 169 & 172 \\
\hline скин-фактор S & $-2,6$ & $-1,8$ & $-2,2$ & 0,02 & 170 & 172 \\
\hline $\begin{array}{c}\text { Мах дебит нефти, } \\
\text { T/сут } \\
\text { Max oil production } \\
\text { rate after RD, } t / \text { day }\end{array}$ & $<10$ & $>10$ & $\begin{array}{c}t \text {-критерий } \\
t \text {-value }\end{array}$ & $p$ & $N_{1}$ & $\mathrm{~N}_{2}$ \\
\hline 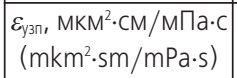 & 0,9 & 2,2 & $-3,5$ & $<0,01 \mid$ & 161 & 181 \\
\hline $\begin{array}{c}K_{\text {прод, }} \mathrm{M}^{3} / \mathrm{cyT} / \mathrm{M} П а \\
\left(\mathrm{~m}^{3} / \mathrm{d} / \mathrm{MPa}\right)\end{array}$ & 1,1 & 2,1 & $-3,4$ & $<0,01 \mid$ & 114 & 141 \\
\hline$\chi, \mathrm{CM}^{2} \cdot \mathrm{c}\left(\mathrm{sm}^{2} \cdot \mathrm{s}\right)$ & 86,3 & 238,4 & $-2,9$ & $<0,01$ & 161 & 181 \\
\hline$P_{\text {пл }}, \mathrm{MПа}(\mathrm{MPa})$ & 10,3 & 11,1 & $-2,0$ & 0,04 & 161 & 180 \\
\hline$P_{\text {заб, }} \mathrm{MПа} \mathrm{(MPa)}$ & 4,2 & 5,4 & $-4,5$ & $<0,01$ & 161 & 181 \\
\hline
\end{tabular}

В табл. 1-3 приведены результаты расчета $t$ критерия. Жирным шрифтом для показателей выделены значения с достигаемым уровнем значимости $p$ ниже 0,05 , при котором с вероятностью более $95 \%$ можно утверждать о различиях в рассмотренных выборках. В этом случае исследуемый параметр оказывает статистически значимое (неслучайное) влияние на различия показателей в выборках. Курсивом выделены значения с $p$ в диапазоне от 0,05 до 0,10 , при которых влияние также существует, но несколько ниже. Символами $N_{1}$ и $N_{2}$ в табл. 1-3 обозначены объемы выборок соответственно для первой и второй групп, $t$-value - значение $t$-критерия. Все скважины и соответствующие им параметры разделены на две примерно равные выборки по одному из показателей эффективности. Статистически незначимые результаты в таблицах не приведены.

Таблица 3. Влияние геологических факторов на продолжительность эффекта для скважин с терригенным коллектором

Table 3. Influence of geological factors on duration of the effect for wells with a terrigenous reservoir

\begin{tabular}{|c|c|c|c|c|c|c|}
\hline $\begin{array}{c}\text { Продолжительность } \\
\text { эффекта от РБ, сут } \\
\text { Duration of the effect } \\
\text { of RD, day }\end{array}$ & $<180$ & $>180$ & $\begin{array}{c}\text { t-критерий } \\
\text { t-value }\end{array}$ & $p$ & $N_{1}$ & $N_{2}$ \\
\hline$K_{n}, \%$ & 17,5 & 15,2 & 2,1 & 0,05 & 17 & 20 \\
\hline$K_{н}$, д.ед. (u.f) & 0,840 & 0,786 & 1,5 & 0,12 & 19 & 21 \\
\hline$k_{\text {гди, }} \mathrm{MKM}^{2}\left(\mathrm{mkm}^{2}\right)$ & 0,333 & 0,210 & 1,8 & 0,07 & 19 & 21 \\
\hline$K_{\text {расч, }}$ ед. $(u)$ & 5,7 & 3,6 & 2,8 & $<0,01$ & 18 & 21 \\
\hline b, д.ед. (u.f) & 1,1 & 1,2 & $-1,8$ & 0,06 & 19 & 21 \\
\hline$h_{\text {пр, }}, \mathrm{M}(\mathrm{m})$ & 0,9 & 1,8 & $-2,2$ & 0,03 & 19 & 21 \\
\hline
\end{tabular}

Обобщая результаты проведенного статистического анализа, можно сделать следующие выводы:

1. Наиболее значимое влияние на технологическую эффективность РБ оказывают:

- нефтенасыщенная толщина;

- вязкость нефти;

- расчлененность;

- коэффициент песчанистости;

- пористость;

- проницаемость УЗП;

- гидропроводность УЗП;

- скин-эффект;

- пьезопроводность;

- коэффициент продуктивности;

- средняя толщина единичного нефтенасыщенного пропластка.

2. По скважинам с карбонатным коллектором (табл. 1) можно сделать выводы, что прирост дополнительной добычи от РБ в целом выше при лучших коллекторских свойствах пород $\left(K_{\text {п }}, K_{\text {пес }}\right)$, в более расчлененном разрезе, а также для менее газонасыщенных (то есть потенциально более вязких) нефтей. Среднесуточный прирост добычи нефти выше при больших нефтенасыщенных толщинах и в более расчлененном разрезе. Продолжительность эффекта выше при лучших коллекторских свойствах залежи $\left(K_{\text {п }}, K_{\text {пест }}, h_{\text {пр }}\right)$ и больших вязкостях нефти. Чем больше нефтенасыщенные толщины, расчлененность разреза, а также выше давление насыщения, тем выше значения максимального дебита нефти после РБ.

В целом, обобщая выше сказанное, для карбонатных залежей технология РБ более эффективна в условиях высокой расчлененности разреза и более вязких нефтей. Именно при таких условиях наиболее вероятно вовлечение в дренирование дополнительных ранее застойных пропластков. При этом лучшие ФЕС коллекторов $\left(K_{\text {п }}, K_{\text {пес }}, h_{\text {пр }}\right)$, характеризуя потенциал работы скважины, также 
способствуют повышению эффективности технологии.

Объем дополнительной добычи (табл. 2) выше при более высоких значениях продуктивности и гидропроводности ПЗП, пьезопроводности пласта, потенциала забойного давления, при относительно ухудшенном состоянии ПЗП. Статистически значимое влияние на среднесуточный прирост оказывают все гидродинамические параметры. Чем больше энергетический потенциал залежи (высокие $P_{\text {пл }}, P_{\text {заб }}$ ) и относительно хуже состояние ПЗП, тем больший технологический эффект наблюдается от применения технологии РБ.

Продолжительность эффекта выше при более высоких забойных и пластовых давлениях, в условиях относительно ухудшенных ПЗП (параметр $S$ ). Чем выше значения гидродинамических параметров и давлений, тем выше значение максимального дебита нефти после РБ.

3. По скважинам с терригенным коллектором

(табл. 3) можно сделать вывод, что статистически значимое влияние геологических параметров установлено только на продолжительность эффекта от РБ. Время эффекта технологии РБ в терригенных коллекторах больше при худших коллекторских свойствах пород $\left(K_{\text {п }}, K_{\text {н }}, k_{\text {гди }}\right)$, при меньшей расчлененности разреза и большей толщине единичных пропластков.

Для скважин с терригенным коллектором данные по гидродинамическим параметрам пласта есть лишь по 11 скважинам, поэтому статистический анализ по ним не является корректным. В целом для оценки эффективности РБ в условиях терригенного коллектора на настоящий момент мало фактического материала.

4. Влияние геологических и гидродинамических параметров более статистически значимо в карбонатных коллекторах, чем в терригенных. Основной причиной этого является то, что бурение радиального канала в карбонатных коллекторах всегда сопровождается СКО, при этом высокая расчлененность карбонатного разреза способствует при РБ вовлечению в дренирование новых пропластков. В связи с тем, что эффективность СКО в терригенных коллекторах значительно ниже, для них кислотные обработки на изученном фонде скважин с РБ не проводились. Кроме этого, снижению продуктивности скважин в терригенном коллекторе способствуют осыпи канала, а также набухание глин при гидромониторном воздействии.

\section{Оценка влияния технологических параметров} на эффективность технологии радиального бурения

В отчетности нефтедобывающих предприятий к технологии РБ, в том числе, относят мероприятия, проводимые в новом интервале перфорации. Очевидно, что при этом к работе приобщаются пропластки с наиболее высокими остаточными запасами. Соответственно в этом случае эффект будет обусловлен не столько РБ, сколько увеличением ох- вата пласта вытеснением нефти по толщине. Для подтверждения этого скважины были разделены на группы с проведением РБ в старом и новом интервале перфорации. В результате для рассмотренных групп установлены статистически значимые различия.

По максимальному дебиту после РБ средние значения различаются на 2,2 т/сут $(11,4$ и 13,6 т/сут соответственно) при $p=0,03$. По времени работы с эффектом различия в средних значениях 239 суток (средние значения 1028 и 1267 сут) при $p=0,02$. Также установлены значимые различия (4303,7 против 5724,3 тонн) по величинам дополнительной добычи $(p=0,14)$. Таким образом, работы в новом интервале характеризуются ощутимо большим эффектом, ввиду чего при оценке эффективности РБ такие скважины надо исключать из анализа. Это же относится к скважинам с дополнительным дострелом пропластков, при котором эффект в основном будет определяться увеличением работающей толщины пласта. В целом необходимо заметить, что дострелы интервалов перфорации не относятся к тематике данной работы, а при статистическом анализе их необходимо вычленять и исключать из обучающей выборки.

Очевидно, что значительное влияние на эффективность любого мероприятия на скважине должны оказывать предыдущие ГТМ. Для таких скважин часть потенциального прироста уже получено от предыдущих ГТМ, что закономерно снижает эффект и должно учитываться при планировании мероприятий. Для карбонатных объектов в Пермском крае длительное время основным методом ПНП являлась соляно-кислотная обработка. Анализ влияния проведенных ранее СКО на эффективность РБ проводился за период с 1997 г. по настоящее время. Все скважины с технологией РБ были разделены на группы: с ранее проведенной $\left(N_{1}=111\right)$ и без СКО $\left(N_{2}=219\right)$.

В результате установлено, что по скважинам с ранее проведенной СКО эффект от РБ по показателям дополнительной добычи $(2192,2$ против 2957,8 т) и среднесуточному приросту $(2,5$ т/сут против 3,1 т/сут) значительно ниже. Этот факт необходимо учитывать при проектировании РБ на скважинах, а также при прогнозных расчетах экономической эффективности. С учетом этого основной для анализа эффективности технологии РБ принималась выборка скважин, для которых данное ГТМ является первым (219 скважин). Скважины с повторными ГТМ исключались из статистического анализа, для таких скважин предлагается вводить понижающую поправку в технологических показателях эффекта.

\section{Разработка методики прогноза эффекта от технологии РБ}

С целью прогнозирования эффекта от технологии РБ для скважин с карбонатным коллектором построены палетки динамики темпа падения прироста дебита. Необходимо заметить, что карбона- 
тные коллекторы для территории исследования весьма неоднородны как по своим структурным, так и фильтрационно-емкостным свойствам. Анализ показывает целесообразность разделения статистической выборки на три группы в зависимости от возраста: башкирского, турнейского и фаменского. Эффективность технологии РБ оценивалась раздельно для выделенных групп карбонатных коллекторов.

Коллекторы башкирского возраста преимущественно представляют собой биоморфно-водорослевые, фораминиферовые разности известняков. Высокоперспективные на наличие углеводородов земли комплекса приурочены к рифогенным зонам Камско-Кинельской системы прогибов в южной половине территории и в Соликамской депрессии. Коллекторы относятся к поровому типу, пористость представлена внутриформенными и межформенными пустотами. Поры в основном крупные, в разрезе круглые, открытые [18].

Залежи турнейского комплекса приурочены к структурам облекания рифогенных сооружений или к тектоногенным поднятиям на юге Пермского края. Формирование коллекторов происходило преимущественно в условиях мелкого моря с устойчивым медленным опусканием дна морского бассейна, в процессе которого происходило накопление слоистой толщи карбонатных осадков. Комплекс сложен слоистыми известняками и доломитами с включением гипсов и ангидритов.

Залежи фаменских отложений представляют собой скопления пористых и кавернозных коллекторов в теле позднедевонских рифовых сооружений Соликамской депрессии. На коллекторские свойства фаменских отложений в большой мере оказывают влияние трещиноватость и кавернозность пород $[19,20]$. При этом на одной и той же залежи могут быть встречены интервалы и с поро- вым, и с трещинным типом коллектора, что определяется литолого-фациальными условиями осадконакопления [21].

На рис. 2-4 раздельно для залежей пластов Бш, Т и Фм построены палетки динамики среднесуточного прироста дебита от РБ во времени. При этом для каждого типа залежей вся выборка разбита на классы по показателю «общая дополнительная добыча от РБ». По всем скважинам в каждом классе взято среднее значение прироста дебита по годам эффекта начиная с года проведения мероприятия. В результате построена линия падения среднесуточного прироста дебита по годам. На основании значений начальных приростов ГТМ можно прогнозировать среднесуточный прирост по годам, время эффекта и дополнительную добычу. При этом предлагается использовать следующий алгоритм. Значение начального прироста откладывается на палетке, и проводится конгруэнтная линия падения әффекта без пересечений с существующими линиями. Палетки по объектам представлены на рис. 2-4.

На основании рис. 2-4 можно сделать вывод, что для залежей рифового типа пласта Фм (рис. 4) эффект, как правило, наиболее значителен в первый год, но имеет высокий темп падения и наименее продолжителен во времени (не более 8 лет). Для залежей пластов Бш (рис. 2) и Т (рис. 3) время әффекта может достигать 11 лет. Для турнейских залежей снижение эффекта характеризуется наименьшим темпом падения добычи. Соответственно при одинаковом начальном приросте для залежей пласта Т общая дополнительная добыча ожидается выше. С помощью представленных палеток можно прогнозировать во времени приросты добычи нефти, что позволяет оценить экономическую эффективность метода.

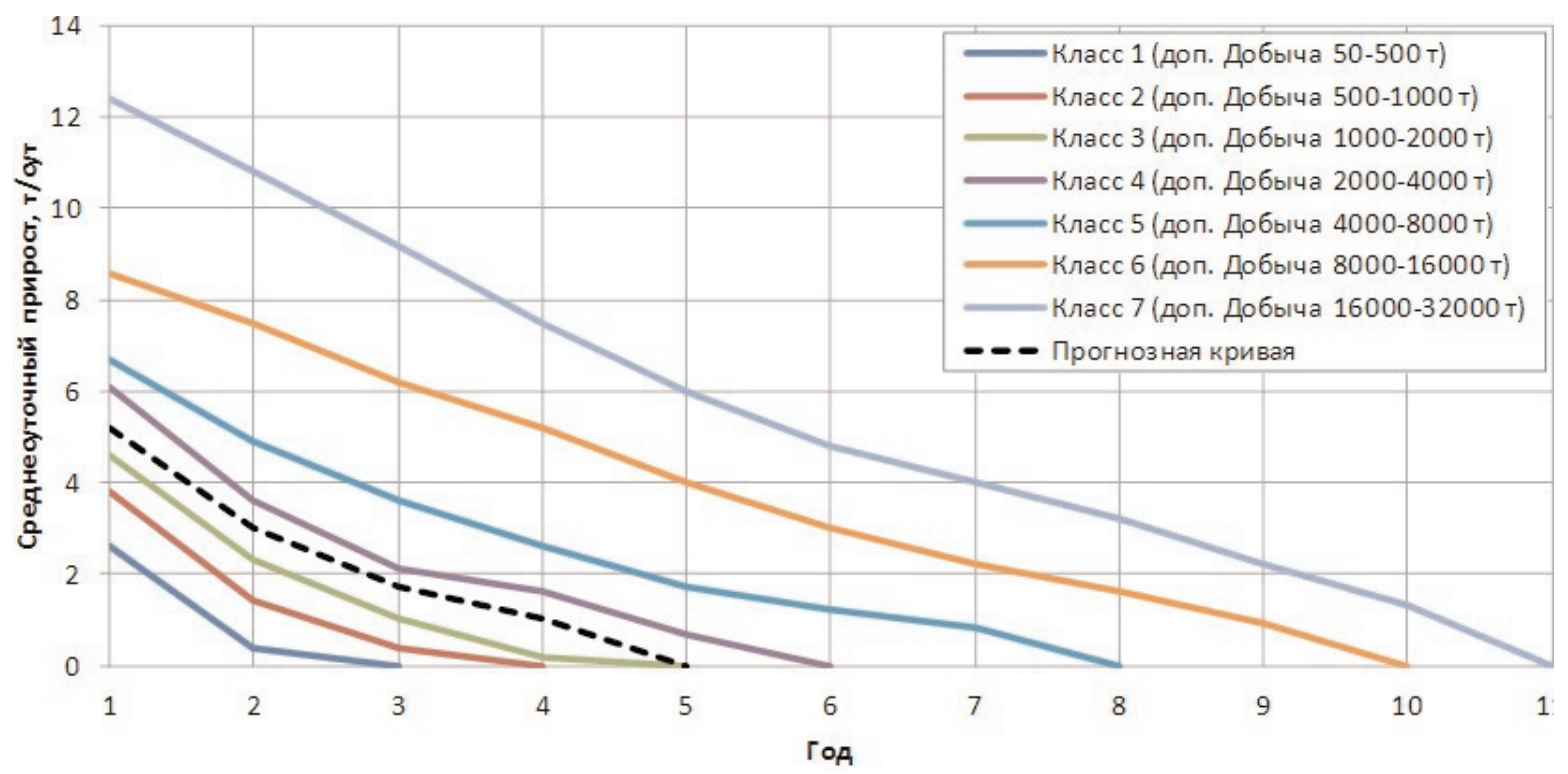

Рис. 2. Палетка прогноза среднесуточного прироста нефти. Объект Бш

Fig. 2. Schedule of oil average daily growth forecast. The object Bs 


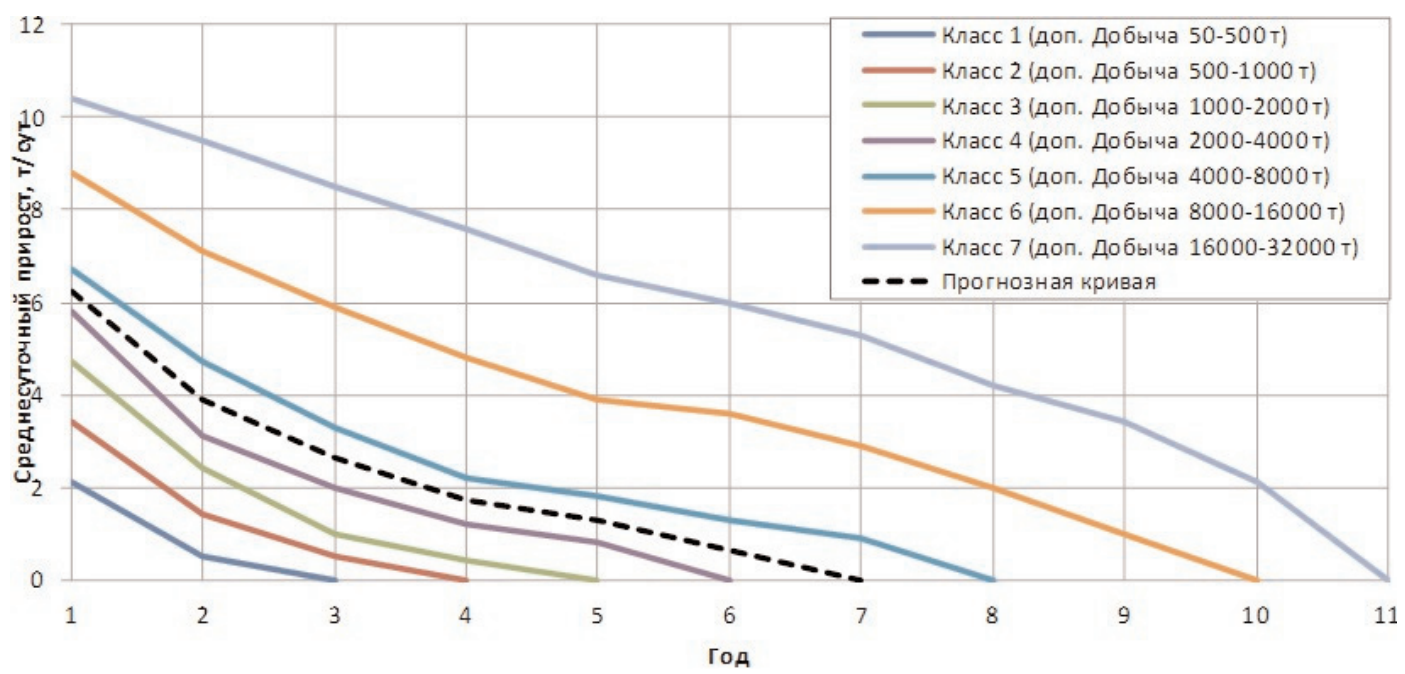

Pис. 3. Палетка прогноза среднесуточного прироста нефти. Объект Т

Fig. 3. Schedule of oil average daily growth forecast. The object $T$

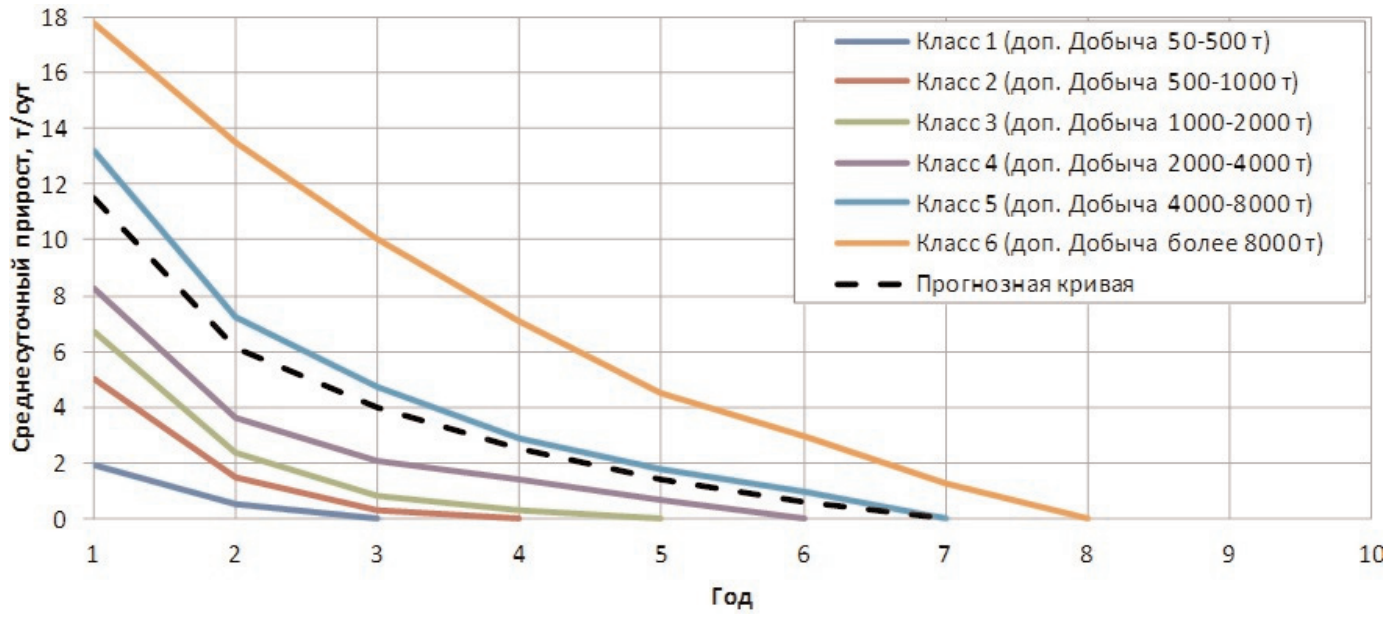

Рис. 4. Палетка прогноза среднесуточного прироста нефти. Объект Фм

Fig. 4. Schedule of oil average daily growth forecast. The object Fm

\section{Заключение}

В ходе исследований создана общая база, включающая все скважины, на которых проводилась технология РБ, а также соответствующие им геологические, гидродинамические и технологические параметры. Проведен анализ эффективности технологии для месторождений Пермского края. Выявлены возможные причины низкой эффективности технологии, а также геологические, гидродинамические и технологические параметры, которые оказывают наибольше влияние на показатели технологической эффективности радиального бурения для скважин с карбонатным типом коллектора.

Установлено, что для карбонатных коллекторов технология РБ более эффективна в условиях высокой расчлененности разреза, при повышенных вязкостях нефти и лучших ФЕС коллекторов $\left(K_{\text {п }}, K_{\text {песч}}, h_{\text {пр }}\right)$. Технология РБ эффективна в условиях скважин с ухудшенным состоянием ПЗП, так как направлена именно на решение данной проблемы. Также положительно влияют на потенциаль- ный эффект от технологии высокие гидродинамические показатели УЗП и энергетический потенциал залежи (высокие $P_{\text {пл) }}$ ).

В терригенном коллекторе установлено влияние геологических параметров только на время эффекта, которое выше при худших коллекторских свойствах пород $\left(K_{\text {п }}, K_{\text {н }}, k_{\text {гди }}\right)$, при меньшей расчлененности разреза и большей толщине единичных пропластков.

Проведена оценка технологических особенностей на эффективность РБ. Установлена необходимость исключения из анализа мероприятий, проводимых в новых интервалах перфорации и при дострелах пластов. Установлено влияние проведенных ранее СКО на эффективность последующего проведения РБ.

Для залежей пластов Бш, Т, Фм построены палетки динамики среднесуточного прироста дебита от РБ во времени, позволяющие оценить вероятное время эффекта и спрогнозировать конечную дополнительную добычу от РБ. 


\section{СПИСОК ЛИТЕРАТУРЫ}

1. Анализ проведения геолого-технических мероприятий по увеличению продуктивности добывающих скважин на нестяных месторождениях Пермского края / П.Ю. Илюшин, Р.М. Рахимзянов, Д.Ю. Соловьев, И.Ю. Колычев // Вестник Пермского национального исследовательского политехнического университета. Геология. Нефтегазовое и горное дело. - 2015. T. 14. - № 15. - С. 81-89.

2. Павельева О.Н., Попова Ж.С. Анализ әффективности применения усовершенствованной технологии бурения глубоких радиальных каналов на Вахитовском месторождении // Геология и нефтегазоносность Западно-Сибирского мегабассейна (опыт, инновации): материалы десятой международной научно-технической конференции (посвященной 60-летию Тюменского индустриального университета). - Тюмень, 2016. - С. 112-115.

3. Сабитов Р.Р., Швечиков Е.Д. Модель принятия решений на основе линейной регрессии для планирования повторного ГРП объекта ЮВ 1 Нивагальского месторождения / Известия Томского политехнического университета. - 2015. - Т. 326. № 3. - C. 122-127.

4. Maximum drillable length of the radial horizontal micro-hole drilled with multiple high-pressure water jets / Huanpeng Chi, Gensheng Li, Zhongwei Huang, Shouceng Tian, Xianzhi Song // Journal of Natural Gas Science and Engineering. - V. 26. 2015. - P. 1042-1049.

5. A numerical simulator developed for modeling permeability control for enhanced oil recovery / T. Brantson, B. Ju, Y. Yang, J. Chi // Journal of Petroleum Science and Engineering. 2017. - V. 159. - P. 360-375.

6. Иванов В.А. Система разработки малопродуктивного зонально-неоднородного нефтяного пласта // НТЖ Нефтепромысловое дело. - 2012. - № 8. - С. 5-11.

7. Field production results with the ultrashort radius radial system in unconsolidated sandstone formations / W. Dickinson, R. Dickinson, J. Nees, E. Dickinson, H. Dykstra // Proc. of the $5^{\text {th }}$ UNITAR International Conference on Heavy Crude and Tar Sands. Caracas, Venezuela, 1991. - V. II. - P. 307-326.

8. Dickinson W., Dykstra H., Nodlund R. Coiled-tubing radials placed by water-jet drilling: Field results, theory and practice // SPE. - 1993. - № 26348. - P. 343-355.

9. Dickinson W., Dykstra H., Nees J.M. The Ultrashort Radius Radial System Applied to Thermal Recovery of Heavy Oil // SPE. 1992. - № 24087. - P. 56-59.

10. Dickinson W., Dickinson R. Horizontal Radial Drilling System // SPE. - 1985. - № 13949. - P. 36-39.

11. Бурение глубоких радиальных каналов. Вскрытие продуктивных пластов низкопроницаемых коллекторов / Н. Демяненко,
А. Серебренников, П. Повжик, М. Галай, Д. Третьяков, С. Клочков // Oil and Gas Journal. - 2016. - № 7. - С. 52-56.

12. Распопов А.В., Кондратьев С.А., Новокрещенных Д.В. Влияние геолого-физических условий на әффективность бурения радиальных каналов в околоскважинную зону пласта // Нефтяное хозяйство. - 2012. - № 3. - С. 78-79.

13. Новокрещенных Д.В., Распопов А.В. Перспективы развития технологий радиального вскрытия пласта на месторождениях Пермского края // Нефтяное хозяйство. - 2014. - № 3. C. $54-57$.

14. Мухаметшин В.В. Устранение неопределенностей при решении задач воздействия на призабойную зону скважин // Известия Томского политехнического университета. Инжиниринг георесурсов. - 2017. - Т. 328. - № 7. - С. 40-50.

15. Elliott S. Coiled-tubing method drills radial laterals to improve oil production from a depleted reservoir // World Oil. - 2011. V. 232. - № 10. - C. 57-64.

16. Kohar J.P., Gogoi S. Radial drilling technique for improving recovery from existing oil fields // International journal of scientific \& technology research. - 2014. - V. 3. - Iss. 11. - P. 159-161.

17. Effects of the wellbore parameters of radial horizontal micro-holes on the gas reservoir production rate / Huanpeng Chi, Gensheng Li, Zhongwei Huang, Shouceng Tian, Xianzhi Song // Journal of Natural Gas Science and Engineering. - 2015. V. 24. - P. 518-525.

18. Estimation of heterogeneity of oil \& gas field carbonate reservoirs by means of computer simulation of core x-ray tomography data / A.A. Efimov, S.V. Galkin, I.V. Savitckii, V.I. Galkin // Ecology, Environment and Conservation. - 2015. - V. 21 (Nov. Suppl.). - P. 79-85.

19. Галкин В.И., Пономарева И.Н. Изучение фильтрационно-емкостных свойств трещиновато-поровых коллекторов турнейско-фаменских объектов месторождений Соликамской депрессии // Нефтяное хозяйство. - 2016. - № 11. - С. 88-91.

20. Определение параметров трещиноватости пород на основе комплексного анализа данных изучения керна, гидродинамических и геофизических исследований скважин / С.С. Черепанов, И.Н. Пономарева, А.А. Ерофеев, С.В. Галкин // Нефтяное хозяйство. - 2014. - № 2. - С. 94-96.

21. Черепанов С.С. Комплексное изучение трещиноватости карбонатных залежей методом Уоррена-Рута с использованием данных сейсмического анализа (на примере турне-фаменской залежи Озерного месторождения) // Вестник Пермского национального исследовательского политехнического университета. Геология. Нефтегазовое и горное дело. - 2015. - Т. 14. № 14. - C. 6-12.

Поступила 11.04.2018 г.

\section{Информация об авторах}

Кочнев A.A., аспирант, ассистент кафедры геологии нефти и газа Пермского национального исследовательского политехнического университета.

Зотиков В.И., доцент кафедры геологии нефти и газа Пермского национального исследовательского политехнического университета.

Галкин $\boldsymbol{C . B . , ~ д о к т о р ~ г е о л о г о - м и н е р а л о г и ч е с к и х ~ н а у к , ~ п р о ф е с с о р , ~ д е к а н ~ г о р н о - н е ф т я н о г о ~ ф а к у л ь т е т а ~ П е р м с к о - ~}$ го национального исследовательского политехнического университета. 


\title{
ANALYSIS OF THE INFLUENCE OF GEOLOGICAL-TECHNOLOGICAL PARAMETERS ON THE EFFECTIVENESS OF RADIAL DRILLING TECHNOLOGY ON THE EXAMPLE OF OPERATIONAL OBJECTS IN PERM REGION
}

\author{
Alexander A. Kochnev', \\ sashakoch93@gmail.com \\ Vladimir I. Zotikov', \\ vladimirzotikov@yandex.ru \\ Sergey V. Galkin', \\ doc_galkin@mail.ru \\ 1 Perm National Research Polytechnic University, \\ 29, Komsomolsky avenue, Perm, 614990, Russia.
}

The relevance. Oil production at the fields in Perm region is falling, it is necessary to use actively the methods for improving oil recove$r y$. There are many methods, among them: acid treatments, hydraulic fracturing, fracturing, radial drilling. To engage non-drained areas in exploration, the sidetracking, multi-hole drilling and various types of fracturing are increasingly used now. However, such operations are quite expensive and not always efficient. The technology of radial drilling is a much cheaper alternative to these measures. The method of radial drilling with proper selection of wells-candidates may be very effective. If it is successfully used, it is possible to use non-drainable interlayers, thereby increasing the recoverable reserves. Radial drilling is not effective at all wells, as there are still no clear criteria for its successful application of radial drilling. The analysis of the technology effectiveness with the development of recommendations for use can significantly improve the success of radial drilling.

The main aim of the research is identification of geological, hydrodynamic and technological parameters for successful application of radial drilling in the fields of Perm region.

Object of research is oil-producing wells of the Perm region deposits where radial drilling operations were carried out.

Method of the research is based on the use of known methods of mathematical statistics.

Results. The authors have analyzed the radial drilling effectiveness in Perm region. A common base for radial drilling was developed. It includes geological, hydrodynamic and technological parameters. The parameters that have the strongest influence on the success of the event are singled out. The authors developed the recommendations for the use of this technology in Perm region.

Key words:

Radial drilling, acidizing of wells, oil production, Student's t-test, production rate, methods of enhanced oil recovery.

\section{REFERENCES}

1. Ilyushin P.Yu., Rakhimzyanov R.M, Soloviev D.Yu., Kolychev I.Yu. Analysis of geological and technical measures to increase the productivity of production wells in the oil fields of the Perm Territory. Bulletin of the Perm National Research Polytechnic University. Geology. Oil and gas and mining, 2015, vol. 14, no. 15, pp. 81-89. In Rus.

2. Pavelieva 0.N., Popova Zh.S. analiz effektivnosti primeneniya usovershenstvovannoy tekhnologii bureniya glubokikh radialnykh kanalov no Vakhitovskom mestorozhdenii [Analysis of the effectiveness of application of advanced deep-radial channel drilling technology at the Vakhitovskoye deposit]. Geologiya i neftegazonosnost Zapodno-Sibirskogo megabasseyna (opyt, innovatsii). Materialy desyatoy mezhdunarodnoy nauchno-tekhnicheskoy konferentsii (posvyashchennoy shestidesyatiletiyu Tyumenskogo industrialnogo universiteta) [Geology and oil and gas content of the West Siberian megabasin (experience, innovations). Materials of the tenth international scientific and technical conference (dedicated to the $60^{\text {th }}$ anniversary of the Tyumen Industrial University)]. Tymen, 2016. pp. 112-115.

3. Sabitov RR, Shvchikov E.D. Model of decision-making on the basis of linear regression for planning of repeated fracturing of object SE 1 of the Nivagalsky deposit. Bulletin of the Tomsk Polytechnic University, 2015, vol. 326, no. 3, pp. 122-127. In Rus.

4. Huanpeng Chi, Gensheng Li, Zhongwei Huang, Shouceng Tian, Xianzhi Song Maximum drillable length of the radial horizontal microhole drilled with multiple high-pressure water jets. Journal of Natural Gas Science and Engineering, 2015, vol. 26, pp. 1042-1049.
5. Brantson T., Ju B., Yang Y., Chi J. A numerical simulator developed for modeling permeability control for enhanced oil recovery. Journal of Petroleum Science and Engineering, 2017, vol. 159 , pp. $360-375$.

6. Ivanov V.A. System development of a low-productivity zonalinhomogeneous oil reservoir. Oilfield business, 2012, no. 8, pp. 5-11. In Rus.

7. Dickinson W., Dickinson R., Nees J., Dickinson E., Dykstra H. Field production results with the ultrashort radius radial system in unconsolidated sandstone formations. Proc. of the $5^{\text {th }}$ UNITAR International Conference on Heavy Crude and Tar Sands. Caracas, Venezuela, 1991. Vol. II, pp. 307-326.

8. Dickinson W., Dykstra H., Nodlund R., Coiled-tubing radials placed by water-jet drilling: Field results, theory and practice. SPE, 1993, no. 26348, pp. 343-355.

9. Dickinson W., Dykstra H., Nees J.M. The Ultrashort Radius Radial System Applied to the Thermal Recovery of Heavy Oil. SPE, 1992, no. 24087, pp. 56-59.

10. Dickinson W., Dickinson R. Horizontal Radial Drilling System. SPE, 1985, no. 13949, pp. 36-39.

11. Demyanenko N., Serebrennikov A., Povzhik P., Galai M., Tretyakov D., Klochkov S. Drilling of deep radial canals. Opening of productive layers of low-permeability reservoirs. Oil and Gas Journal, 2016, no. 7, pp. 52-56. In Rus.

12. Raspopov A.V., Kondratiev S.A., Novokreshcheny D.V. Influence of geological and physical conditions on the efficiency of drilling radial canals in the near-wellbore zone of the reservoir. Oil Industry, 2012, no. 3, pp. 78-79. In Rus. 
13. Novokreshchenny D.V., Raspopov A.V. Perspectives of development of technologies of radial opening of a layer on deposits of the Perm edge. Oil industry, 2014, no. 3, pp. 54-57. In Rus.

14. Mukhametshin V.V. Elimination of uncertainties in solving the problems of impact on the bottomhole well zone. Bulletin of the Tomsk Polytechnic University. Geo Assets Engineering, 2017, vol. 328 , no. 7, pp. 40-50.

15. Elliott S. Coiled-tubing method drills radial laterals to improve oil production from a depleted reservoir. World Oil, 2011, vol. 232 , no. 10 , pp. 57-64

16. Kohar J.P., Gogoi S. Radial drilling technique for improving recovery from existing oil fields. International journal of scientific \& technology research, 2014, vol. 3, Iss. 11, pp. 159-161.

17. Huanpeng Chi, Gensheng Li, Zhongwei Huang, Shouceng Tian, Xianzhi Song. Effects of the wellbore parameters of radial horizontal micro-holes on the gas reservoir production rate. Journal of Natural Gas Science and Engineering, 2015, vol. 24, pp. 518-525.

18. Efimov A.A., Galkin S.V., Savitckii I.V., Galkin V.I. Estimation of heterogeneity of oil and gas field carbonate reservoirs by means of computer simulation of core x-ray tomography data. Ecology, Environment and Conservation, 2015, vol. 21 (Nov. Suppl.), pp. 79-85.

19. Galkin V.I., Ponomareva I.N. Study of the filtration-capacitive properties of the fractured-pore collectors of the Tournaisian-Famennian deposits of the Solikamsk depression deposits. Oil Industry, 2016, no. 11, pp. 88-91. In Rus.

20. Cherepanov S.S., Ponomareva I.N., Erofeev A.A., Galkin S.V. Determination of fracture parameters of rocks on the basis of complex analysis of core data, hydrodynamic and geophysical studies of wells. Oil Industry, 2014, no. 2, pp. 94-96. In Rus.

21. Cherepanov S.S. A comprehensive study of the fracturing of carbonate deposits by the method of Warren-Rut using seismic analysis data (on the example of the tour-Fama deposit of the Ozernoe deposit). Vestnik of the Perm National Research Polytechnic University. Geology. Oil and gas and mining, 2015, no. 14, pp. 6-12. In Rus.

Received: 11 April 2018.

\section{Information about the authors}

Alexander A. Kochnev, graduate student, assistant, Perm National Research Polytechnic University.

Vladimir I. Zotikov, associate professor, Perm National Research Polytechnic University.

Sergey V. Galkin, Dr. Sc., professor, Dean of the Mining and Petroleum Department, Perm National Research Polytechnic University. 